\title{
Note from the Editor-in-Chief: Changes to reviewing manuscripts and the submission system for Journal of Transport and Health
}

One of the interesting facets of being a multi-disciplinary journal is melding expectations of researchers from different backgrounds. One example has been surprise that authors' identities has been revealed to reviewers. A discussion in 2015 among Board members considered moving to open review, where reviewers' names are also disclosed. Opinion was very divided but the majority view was to move instead to a double blind system, where neither the reviewers nor the authors know the others' identity. This was partly because of concern whether individuals would be willing to review manuscripts without anonymity in an open review system. More important was the awareness that cognitive bias in assessment of scientific work, specifically social bias, as described by Lee et al (2013), could unwittingly disadvantage certain groups of authors. I took the decision to delay this change until the Journal of Transport and Health moved from the current EES submission system to the new EVISE system that is replacing it. This change-over occurred in June 2016. EES will remain in use for manuscripts already in that system but all new submissions are now handled through EVISE. Moving to double blind reviewing has also required some changes to how you format manuscripts. The title page now needs to be a separate file, so that the main text file is anonymous (and needs to be anonymised if the content would identify you).

- To submit a new manuscript to this journal, register on EVISE and submit your manuscript at www.evise.com/evise/jrnl/JTH. Training is available for authors and reviewers at http://www.evise.com/elearning/standalone.html .

- Please continue to use EES for resubmitting revised manuscripts that have previously been reviewed through the EES system (http://ees.elsevier.com/ith/default.asp).

We are also taking the opportunity of revising the Guide for Authors to ask all authors to give some thought as to the implications of their study for policy-makers and practitioners. Authors are therefore now required to aim at least one of their highlights for policy-makers and practitioners and to include a paragraph in their discussion on the relevance or impact of the study for policy and/or practice. There will be a few articles, perhaps focussing on methodology, where this does not apply but we expect such articles to be a small minority - and to explain why it is not relevant in the covering letter.

The social bias referred to above differs from the confirmatory bias reported by Mahoney (1977), which showed that reviewers are more likely to affirm research reports whose results confirm the reviewers' existing beliefs on a topic. We are sure that our reviewers are aware of such risks and review their allocated manuscripts in an impartial way, assessing the appropriateness of the study design and the way it was conducted, the scientific robustness of the findings, and the pertinence of the conclusions.

Dr Jennifer Mindell

Editor-in-Chief

\section{References}

Lee CJ, Sugimoto CR, Zhang G, Cronin B. (2013) Bias in Peer Review. Journal of the American Society for Information Science and Technology. 64(1):2-17, 2013.

Mahoney MJ (1977). Publication Prejudices: An Experimental Study of Confirmatory Bias in the Peer Review System Cognitive Therapy and Research.1(2): 161-175. 